\title{
Nanostructured metal oxide/conjugated polymer hybrid solar cells by low temperature solution processes
}

\author{
Yun-Yue Lin, ${ }^{a}$ Chun-Wei Chen, ${ }^{* a}$ Tsung-Hung Chu, ${ }^{a}$ Wei-Fang Su, ${ }^{* a}$ Chih-Cheng Lin, ${ }^{a b}$ Chen-Hao Ku, \\ Jih-Jen $\mathrm{Wu}^{b}$ and Cheng-Hsuan Chen ${ }^{c}$
}

Received 9th July 2007, Accepted 22nd August 2007

First published as an Advance Article on the web 7th September 2007

DOI: $10.1039 / b 710400 f$

In this article, we have proposed a nanostructured photovoltaic device based on the $\mathrm{ZnO}$ nanostructures/poly(3-hexylthiophene)(P3HT): $\mathrm{TiO}_{2}$ nanorod hybrid by solution processes at low temperature. An array of $\mathrm{ZnO}$ nanorods with a larger size of $\sim 50 \mathrm{~nm}$ in diameter and $\sim 180 \mathrm{~nm}$ in length are grown to provide direct pathways for efficient charge collection. $\mathrm{TiO}_{2}$ nanorods with a size of $\sim 5 \mathrm{~nm}$ in diameter and $\sim 20-30 \mathrm{~nm}$ in length are incorporated into polymers to facilitate charge separation and transport by providing an increased interfacial area and a more effective transport pathway. The device performance with the inclusion of $\mathrm{TiO}_{2}$ nanorods exhibits a seven times increase in the short circuit current with respect to that without $\mathrm{TiO}_{2}$ nanorods. The device performance can be further enhanced after completely removing the residual surfactant on the $\mathrm{TiO}_{2}$ nanorods using the ligand exchange method, giving a short circuit current density of $2.67 \mathrm{~mA} \mathrm{~cm}^{-2}$ and a power conversion efficiency of $0.59 \%$ under Air Mass $1.5\left(100 \mathrm{~mW} \mathrm{~cm}^{-2}\right)$ illumination.

\section{Introduction}

Recently, dye-sensitized solar cells based on nanoporous $\mathrm{TiO}_{2}$ thin films can reach an efficiency as high as $10 \% .{ }^{1}$ However, the requirement of using liquid electrolytes in dye-sensitized solar cells is still a very challenging issue to be resolved for commercial applications. Considerable research has been focused on developing solid state dye-sensitized solar cells or alternatively, polymer solar cells. Polymer solar cells have attracted a great deal of interest recently due to their potential application in developing low-cost, large-area, mechanically flexible photovoltaic devices. ${ }^{2,3}$ A basic requirement for a photovoltaic material is to generate free charge carriers produced by photoexcitation. Subsequently, these carriers are transported through the device to the electrodes without recombining with oppositely charged carriers. Due to the low dielectric constant of organic materials, the dominant photogenerated species in most conjugated polymers is a neutral bound electron-hole pair (exciton). These neutral excitons can be dissociated from Coulomb attraction by offering an energetically favorable pathway for the electron from the polymer (donor) to transfer onto an electron-accepting species (acceptor). Because the diffusion length of excitons in a semiconducting polymer is usually shorter than $20 \mathrm{~nm},{ }^{4-6}$ the electron acceptor must be intermixed with polymer at a nanometre length scale to achieve efficient charge separation. The most commonly used structure is the polymer-based bulk heterojunction (BHJ) solar cell, which consists of an electron-accepting network formed randomly within the

\footnotetext{
${ }^{a}$ Department of Materials Science and Engineering, National Taiwan University 106,Taiwan.E-mail: chunwei@ntu.edu.tw; suwf@ntu.edu.tw ${ }^{b}$ Department of Chemical Engineering, National Cheng Kung University, Tainan, 701, Taiwan

${ }^{c}$ Center for Condensed Matter Sciences, National Taiwan University, Taipei 106, Taiwan
}

polymer matrix. The most popular electron acceptors in $\mathrm{BHJ}$ polymer photovoltaic devices are $\mathrm{C}_{60}$ derivatives ${ }^{7,8}$ and nanocrystals such as $\mathrm{CdSe}^{2,9}$ or $\mathrm{TiO}_{2}{ }^{10-12}$ or $\mathrm{ZnO} .^{13}$ After charge separation, electrons and holes must be transported to the opposite electrode before back recombination occurs. Carrier transport in the $\mathrm{BHJ}$ photovoltaic devices is usually limited by the poorly formed electron conducting pathway through hopping. A promising photovoltaic device structure consisting of a direct and ordered path for photogenerated electrons to the collecting electrode has been proposed. This can be done by using templated porous nanostructures, ${ }^{14-17}$ or vertically oriented nanorods. ${ }^{18-20}$ A maximum external quantum efficiency of $\sim 10 \%$ has been achieved by filling polymer into well-controlled $\mathrm{TiO}_{2}$ nanopores synthesized using block copolymers as the structure directing agent. ${ }^{14}$ However, the infiltration of polymer into the small $\mathrm{TiO}_{2}$ nanopores is still not a trivial task. Recently, $\mathrm{ZnO}$ nanorods grown perpendicularly to the substrate have attracted a great interest since they can be synthesized through simple processes from solution at low temperature. Photovoltaic devices based on conjugated polymer deposited onto $\mathrm{ZnO}$ nanorods ${ }^{19}$ or nanofibers $^{20}$ have been demonstrated recently. Although the optimized structural dimension of less than $20 \mathrm{~nm}$ between nanorods is desirable, it is still very challenging to control the precise spacing between $\mathrm{ZnO}$ nanorods for infiltrating polymer. In ref. 19, an amphiphilic molecular dye interface between $\mathrm{ZnO}$ nanorods and the polymer is therefore required to assist charge separation due to the large film pore sizes $(\sim 100 \mathrm{~nm})$ between nanorods. In this article, we propose a nanostructured photovoltaic device based on the $\mathrm{ZnO} / \mathrm{P} 3 \mathrm{HT}: \mathrm{TiO}_{2}$ hybrid material as shown in Fig. 1 schematically. Thicker $\mathrm{ZnO}$ nanorod arrays are grown on the electrode surface to provide a direct pathway for efficient electron collection. The thinner $\mathrm{TiO}_{2}$ nanorods are then incorporated into polymer to provide larger interfacial areas and more effective conduction 


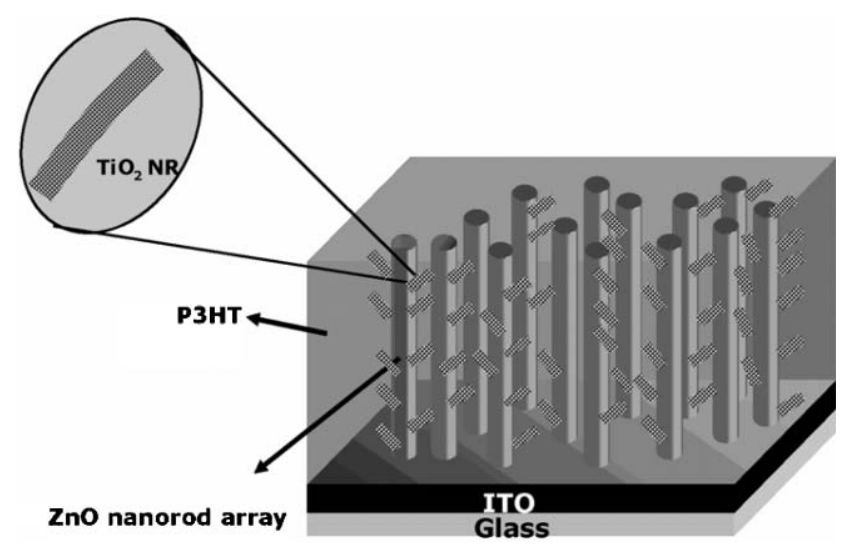

Fig. 1 Schematic representation of the $3 \mathrm{D}$ nanostructured photovoltaic device based on the $\mathrm{ZnO} / \mathrm{P} 3 \mathrm{HT}: \mathrm{TiO}_{2}$ hybrid material.

paths for charge separation and transport respectively. The mechanisms of efficient charge separation and transport in $\mathrm{ZnO} / \mathrm{P} 3 \mathrm{HT}: \mathrm{TiO}_{2}$ nanostructured photovoltaic devices have further been investigated by time-resolved photoluminescence (TRPL) spectroscopy and fast transient photocurrent measurements. Considerable improvement in the device performance can be achieved in the nanostructured hybrid photovoltaic device by infiltrating the $\mathrm{P} 3 \mathrm{HT}: \mathrm{TiO}_{2}$ hybrid material with respect to that obtained by infiltrating the polymer only.

\section{Material preparation and experimental setup}

\section{(1) $\mathrm{TiO}_{2}$ nanorods}

The growth of high aspect ratio anatase titanium dioxide nanorods was achieved by the hydrolysis of titanium tetraisopropoxide according to literature methods..$^{21,22}$ Typically, oleic acid $(120 \mathrm{~g}$, Aldrich, $90 \%)$ was stirred vigorously at $120{ }^{\circ} \mathrm{C}$ for $1 \mathrm{~h}$ in a three-neck flask under Ar flow, then allowed to cool to $90{ }^{\circ} \mathrm{C}$ and maintained at this temperature. Titanium isopropoxide (17 mmole, Aldrich, $99.999 \%$ ) was then added to the flask. After stirring for $5 \mathrm{~min}$, trimethylamine- $N$-oxide dihydrate (34 mmole, ACROS, 98\%) in $17 \mathrm{ml}$ water was rapidly injected. The trimethylamine- $N$-oxide dihydrate was used as a catalyst for polycondensation. The reaction was continued for $10 \mathrm{~h}$ to have complete hydrolysis and crystallization. Finally, the $\mathrm{TiO}_{2}$ nanorods were collected by centrifugation and then redispersed in chloroform. Fig. 2(a) shows the X-ray diffraction (XRD) pattern of $\mathrm{TiO}_{2}$ nanorods [Philips PW3040 with filtered $\mathrm{Cu} \mathrm{K} \alpha$ radiation $(\lambda=1.541 \AA)$ ], indicating the formation of the anatase phase. A sharp peak intensity and narrow width of (004) imply the formation of nanorods. The $\mathrm{TiO}_{2}$ nanorod microstructure was measured by a JEOL2000FX (Japan) transmission electron microscope (TEM) operated at $200 \mathrm{keV}$. The TEM image of $\mathrm{TiO}_{2}$ nanorods in the inset of Fig. 2(a) reveals that the dimensions of the $\mathrm{TiO}_{2}$ nanorods are $20-30 \mathrm{~nm}$ in length and $4-5 \mathrm{~nm}$ in diameter. The high-resolution TEM (HRTEM) image of the $\mathrm{TiO}_{2}$ nanorods is shown in Fig. 2(b). The corresponding selected-area diffraction pattern (SADP) of the $\mathrm{TiO}_{2}$ nanorods is also shown in the inset of Fig. 2(b). The $d$-spacing of this ring pattern is $3.54 \AA$, $2.39 \AA, 1.90 \AA$ and $1.69 \AA$ from inner ring to outer ring. It can (a)

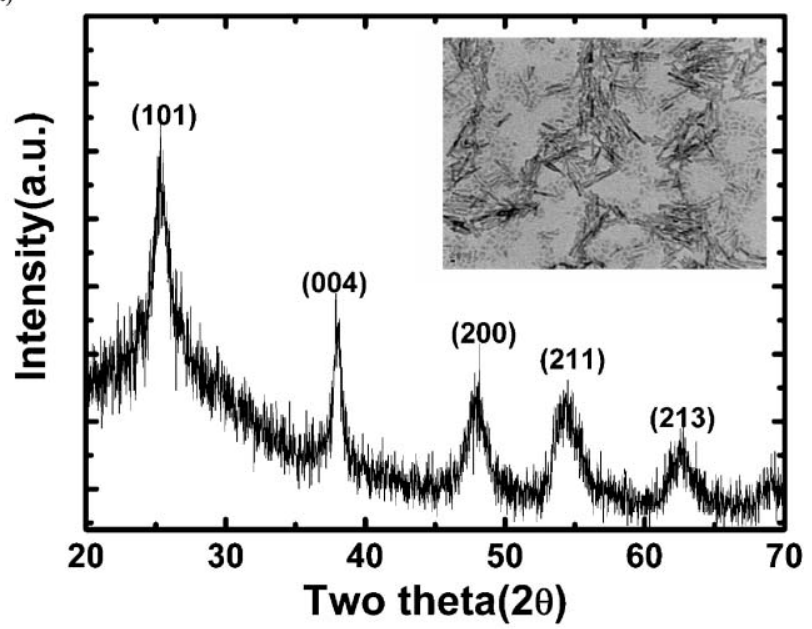

(b)

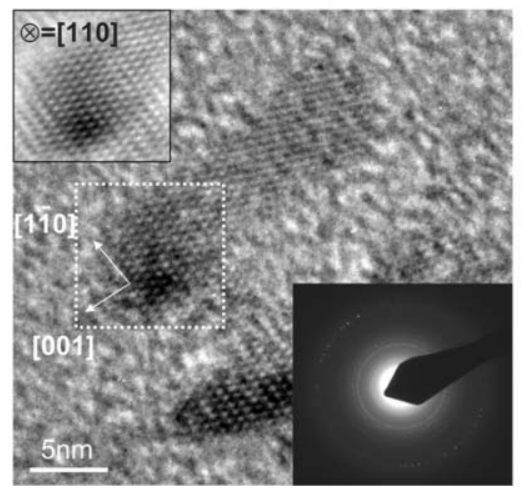

Fig. 2 (a) X-Ray diffraction (XRD) pattern of $\mathrm{TiO}_{2}$ nanorods. The inset shows the TEM image of $\mathrm{TiO}_{2}$ nanorods. (b) High-resolution TEM (HRTEM) image of $\mathrm{TiO}_{2}$ nanorods and the corresponding selected-area diffraction pattern (inset).

be indexed for (101), (004), (200) and (211) of the $\mathrm{TiO}_{2}$ anatase phase, consistent with the XRD result. The filtered image from the square region is also shown, which indicates the growth direction of the $\mathrm{TiO}_{2}$ nanorods is along the longitudinal [001] direction in the synthesized condition. In the preparation of hybrid materials, the P3HT solution was prepared by dissolving P3HT (Aldrich, USA) in chloroform at a concentration of $1 \mathrm{wt} \%$. The hybrid materials were prepared by adding the appropriate amount of $\mathrm{TiO}_{2}$ nanorods to a $1 \mathrm{wt} \%$ polymer solution to make composite samples with a ratio of $1: 1$.

\section{(2) Preparation of $\mathrm{ZnO}$ nanorods}

$\mathrm{ZnO}$ nanorod arrays were grown on Au-coated ITO substrates using a pulsed current electrolysis method. Au layers with a thickness of $\sim 10 \mathrm{~nm}$ were pre-deposited on the ITO substrates using DC sputtering. The substrate, a platinum wire and an $\mathrm{Ag} / \mathrm{AgCl}$ electrode were utilized as the working, the counter and the reference electrodes, respectively, in an electrochemical system. A $0.0025 \mathrm{M}$ aqueous solution of $\mathrm{Zn}\left(\mathrm{NO}_{3}\right)_{2}$ was employed to be the electrolyte. A pulsed wave with a pulse length and a pulse period of 0.01 and $0.1 \mathrm{~s}$, respectively, were used for the growth of $\mathrm{ZnO}$ nanorods. The pulsed current density was $-2 \mathrm{~mA} \mathrm{~cm}^{-2}$. Fig. 3(a) shows the typical scanning 
(a)

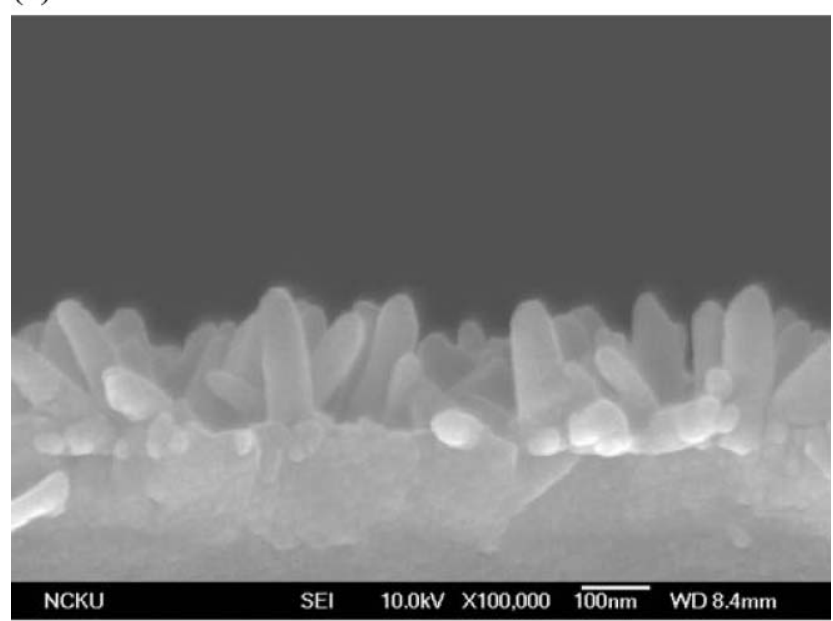

(b)

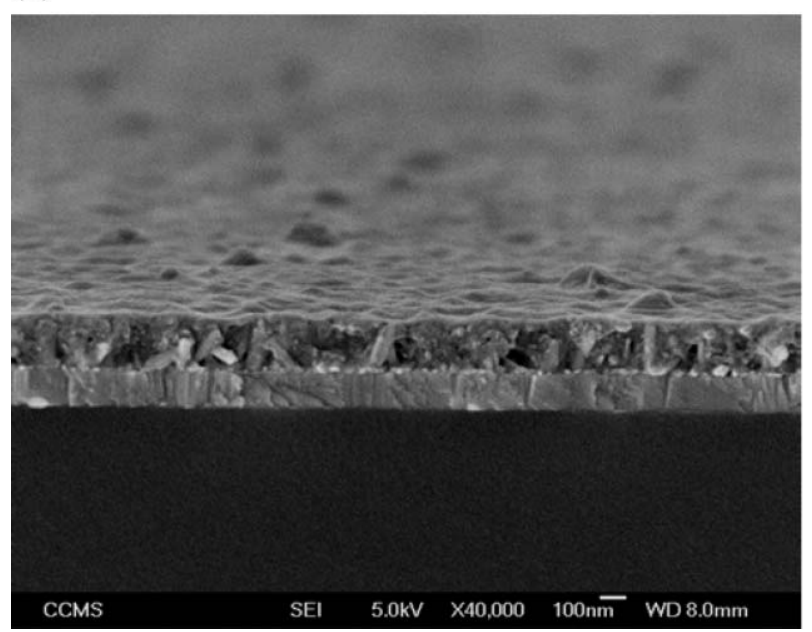

Fig. 3 Cross-sectional SEMs of (a) $\mathrm{ZnO}$ nanorod arrays, (b) $\mathrm{ZnO}$ nanorods after the infiltration of $\mathrm{P}_{3} \mathrm{HT}: \mathrm{TiO}_{2}$ nanorod hybrid.

electron micrograph (SEM) of the $\mathrm{ZnO}$ nanorod array formed using a pulsed current electrolysis method at $80{ }^{\circ} \mathrm{C}$. The diameter and the length of the $\mathrm{ZnO}$ nanorods are about $\sim 50 \mathrm{~nm}$ and $\sim 180 \mathrm{~nm}$, respectively. The average spacing between nanorods is of the order of $\sim 120 \mathrm{~nm}$ (estimated from the top view image).

\section{(3) Device fabrication}

For photovoltaic device fabrication, a thin active layer consisting of the P3HT: $\mathrm{TiO}_{2}$ nanorod hybrid was deposited onto $\mathrm{ZnO}$ nanorods using spin-coating. The sample was then heated at a temperature of $150{ }^{\circ} \mathrm{C}$ for $15 \mathrm{~min}$ to facilitate the infiltration of the P3HT: $\mathrm{TiO}_{2}$ nanorod hybrid. Fig. 3(b) shows the cross-sectional SEM image of the $\mathrm{ZnO}$ nanorods after infiltration of the $\mathrm{P} 3 \mathrm{HT}: \mathrm{TiO}_{2}$ nanorod hybrid. The thin active layer with a thickness of $200 \mathrm{~nm}$ was used as a light absorbing and hole transporting material. The device was then fabricated by spin-coating a layer of PEDOT:PSS with an effective thickness of $50 \mathrm{~nm}$ before thermal evaporation of the Au top electrode. The highly conductive PEDOT:PSS layer is

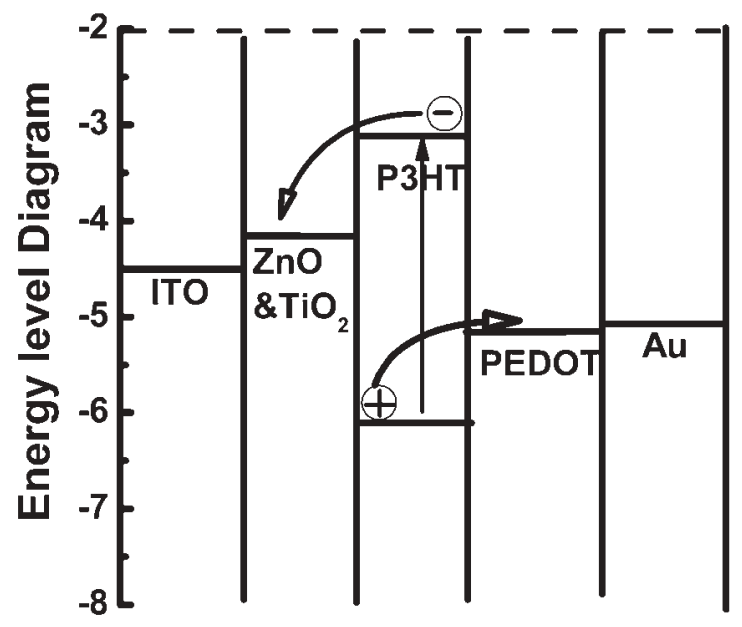

Fig. 4 The corresponding energy levels of the nanostructured photovoltaic device based on $\mathrm{ZnO} / \mathrm{P} 3 \mathrm{HT}: \mathrm{TiO}_{2}$ nanorod hybrid.

intended to keep the serial resistance low and to reduce surface roughness by filling the voids in the films. The films were then baked in a vacuum oven for $6 \mathrm{~h}$ at $120^{\circ} \mathrm{C}$. Vapor deposition of the Au top electrode was then carried out at pressure around $2 \times 10^{-6}$ Torr. The corresponding energy levels obtained from the literature ${ }^{1,19}$ for the nanostructured photovoltaic device based on $\mathrm{ZnO} / \mathrm{P} 3 \mathrm{HT}: \mathrm{TiO}_{2}$ nanorod hybrid are shown in Fig. 4.

\section{(4) Characterization}

UV-Visible absorption spectra were obtained using an Ocean Optics HR-4000 spectrometer. The steady state PL spectra were taken by the FluoroLog $\AA-3$ spectrofluorometer (Jobin-Yvon). Time-resolved photoluminescence spectroscopy was performed with a time-correlated single photon counting (TCSPC) spectrometer (Picoquant, Inc.). A pulse laser $(375 \mathrm{~nm})$ with an average power of $1 \mathrm{~mW}$ operating at $40 \mathrm{MHz}$ with a duration of $70 \mathrm{ps}$ was used for excitation. Current-voltage measurements were obtained using a solar simulator (Oriel Inc.) using the AM 1.5 filter with an irradiation intensity of $100 \mathrm{~mW} \mathrm{~cm}{ }^{-2}$. Fast transient photocurrent measurements ${ }^{23}$ were performed by a frequency-tripled $\mathrm{Nd}$ :YAG pulsed laser $(\lambda=355 \mathrm{~nm}$ and pulse width $\sim 5 \mathrm{~ns})$ and the signals were recorded by a digital oscilloscope (Tetronix TDS5052B). The film thickness was measured by means of the Veeco M6 surface profiler.

\section{Results and discussions}

Fig. 5 shows the normalized absorption spectra of pristine P3HT and $\mathrm{ZnO} / \mathrm{P} 3 \mathrm{HT}: \mathrm{TiO}_{2}$ nanorod hybrid thin films respectively. The pristine P3HT exhibits a broad absorption spectrum ranging from 350 to $650 \mathrm{~nm}$. The enhanced optical density of the absorption spectra below $380 \mathrm{~nm}$ in the hybrid mainly results from the contributions of $\mathrm{ZnO}$ nanorods and $\mathrm{TiO}_{2}$ nanorods. A slight blueshift of the $\mathrm{P} 3 \mathrm{HT}$ band as well as the appearance of a weaker vibronic structure in the hybrid film is mainly attributed to a loss of P3HT polymer-chain stacking after infiltration into $\mathrm{ZnO}$ nanorods and mixing with $\mathrm{TiO}_{2}$ nanorods. As shown in Fig. 4, when the polymer is 


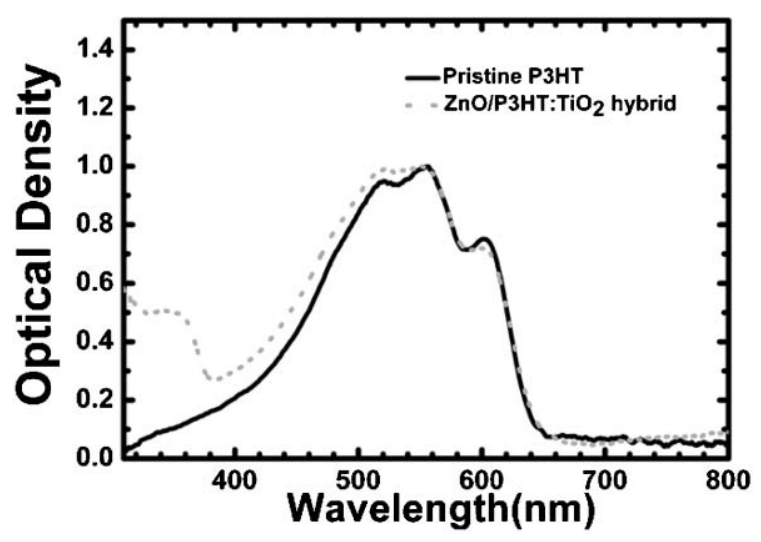

Fig. 5 Normalized absorption spectra of pristine $\mathrm{P} 3 \mathrm{HT}$ and $\mathrm{ZnO} /$ $\mathrm{P} 3 \mathrm{HT}: \mathrm{TiO}_{2}$ nanorod hybrid thin films respectively.

excited, charge separation occurs at the interface between the polymer and the $\mathrm{ZnO}$ (or $\mathrm{TiO}_{2}$ ) nanorods, giving a chargeseparated state with an electron on the $\mathrm{ZnO}$ (or $\mathrm{TiO}_{2}$ ) nanorods and a hole on the polymer. Charge separation efficiency at polymer-inorganic nanocrystal interfaces can be usually revealed through quenching of the photoluminescence (PL) efficiency and shortening of the measured PL lifetime in the polymer. ${ }^{9,24}$ Four samples consisting of different configurations are taken for investigation. Sample A (P3HT) represents the pristine $\mathrm{P} 3 \mathrm{HT}$ thin film deposited on the ITO substrate. Sample B ( $\mathrm{ZnO} / \mathrm{P} 3 \mathrm{HT})$ and Sample C $(\mathrm{ZnO} /$ P3HT: $\mathrm{TiO}_{2}$ ) represent the composites by spin-coating neat P3HT and P3HT:TiO 2 nanorod hybrid thin active layers onto the array of $\mathrm{ZnO}$ nanorods respectively. Sample $\mathrm{D}\left(\mathrm{ZnO} / \mathrm{TiO}_{2} /\right.$ P3HT: $\mathrm{TiO}_{2}$ ) has a similar configuration to Sample $\mathrm{C}$ but is pre-coated with a very thin $\mathrm{TiO}_{2}$ nanorod layer onto $\mathrm{ZnO}$ nanorods before the $\mathrm{P} 3 \mathrm{HT}: \mathrm{TiO}_{2}$ nanorod hybrid layer is deposited. The solution concentration of the pre-coated thin $\mathrm{TiO}_{2}$ nanorods layer is about $10 \mathrm{mg} \mathrm{ml}^{-1}$. After spin-coating the thin $\mathrm{TiO}_{2}$ nanorod layer, the sample is heat treated at a temperature of $120^{\circ} \mathrm{C}$ for $5 \mathrm{~min}$ to remove the residual solvent. All these samples have a similar thickness of about $200 \mathrm{~nm}$. Fig. 6 shows the PL decay spectroscopy for the four different samples. It is found that the PL lifetime $\tau_{\mathrm{B}}(643 \mathrm{ps})$ for Sample $\mathrm{B}$ is shorter than that of the pristine P3HT thin film $\tau_{\mathrm{A}}$ (735 ps), indicating that charge separation occurs at the interfaces between $\mathrm{P} 3 \mathrm{HT}$ and the $\mathrm{ZnO}$ nanorods by providing a new non-radiative process for photogenerated excitons. As $\mathrm{TiO}_{2}$ nanorods are blended with P3HT, a large number of interfaces between the polymer and the $\mathrm{TiO}_{2}$ nanorods are generated, leading to more efficient charge separation as a result of the shorter PL lifetime $\tau_{\mathrm{C}}(509 \mathrm{ps})$ for Sample C compared to $\tau_{\mathrm{B}}$. For Sample D, the PL decay lifetime $\tau_{\mathrm{D}}$ (361 ps) is even shorter than $\tau_{\mathrm{C}}$ due to the increasing number of interfaces on the surface of the $\mathrm{ZnO}$ nanorods by coating a thin $\mathrm{TiO}_{2}$ nanorod layer before infiltrating the active layer. As a result, more efficient exciton dissociation occurs. The role of the thin $\mathrm{TiO}_{2}$ nanorod layer on the $\mathrm{ZnO}$ surface can be as follows. Firstly, inserting this layer can create a second interfacial area for exciton dissociation that might increase the charge transfer rate. In addition, an additional $\mathrm{TiO}_{2}$ nanorod thin film on the $\mathrm{ZnO}$ surface can also act as a hole-blocking layer to prevent

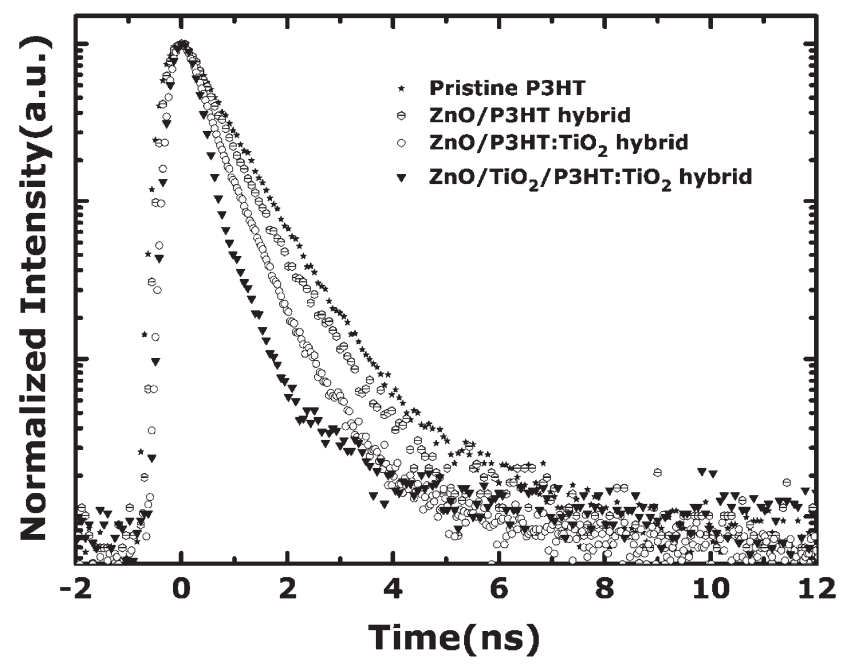

Fig. 6 Time-resolved photoluminescence spectroscopy for the samples consisting of pristine P3HT (Sample A), ZnO nanorods/ P3HT (Sample B), ZnO nanorods/P3HT:TiO 2 nanorod hybrid (Sample C) and $\mathrm{ZnO}$ nanorods $/ \mathrm{TiO}_{2}$ nanorods $/ \mathrm{P} 3 \mathrm{HT}: \mathrm{TiO}_{2}$ nanorod hybrid (Sample D) respectively.

back recombination ${ }^{25}$ and direct contact between the polymer and the ITO electrode.

The photovoltaic performances of the nanostructured devices based on the $\mathrm{ZnO}$ nanorods and $\mathrm{P} 3 \mathrm{HT}: \mathrm{TiO}_{2}$ nanorod hybrid are then characterized under simulated AM 1.5 illumination as shown in Fig. 7. Three devices with different configurations are fabricated for comparison. Device $\mathrm{I}(\mathrm{ZnO} /$ $\mathrm{P} 3 \mathrm{HT}$ ) is based on neat P3HT film deposited onto $\mathrm{ZnO}$ nanorods and exhibits a short circuit current density $\left(J_{\mathrm{sc}}\right)$ of $0.30 \mathrm{~mA} \mathrm{~cm}^{-2}$, an open circuit voltage $\left(V_{\text {oc }}\right)$ of $335 \mathrm{mV}$, a fill factor $(\mathrm{FF})$ of 0.40 , and a power conversion efficiency $(\eta)$ of $0.04 \%$. The $\eta$ of the device with a neat P3HT film deposited onto $\mathrm{ZnO}$ nanorods is similar to that in ref. 19 but is lower compared to that in ref. 20 with a similar configuration. One possible reason for the higher efficiency in ref. 20 may be due

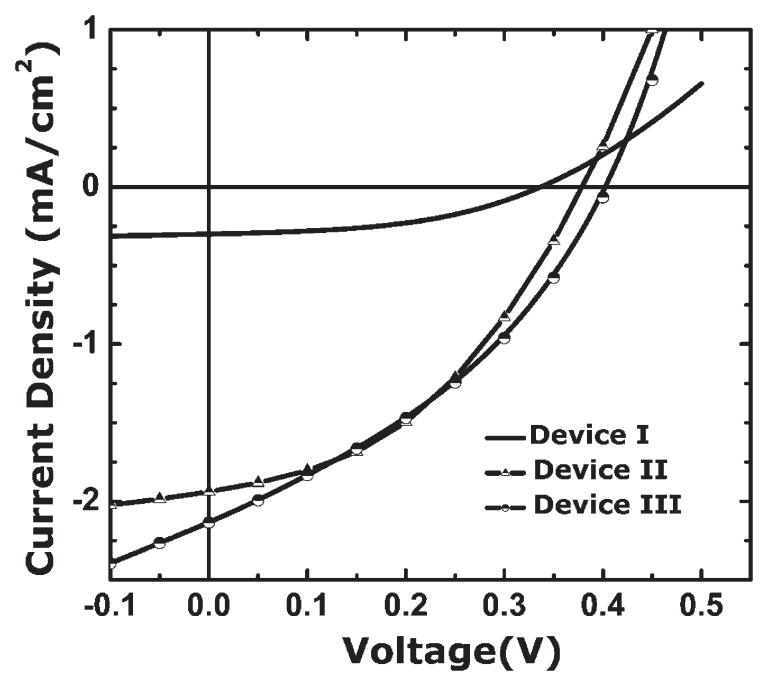

Fig. 7 Photovoltaic performances of devices with different configurations. Device I: ( $\mathrm{ZnO} / \mathrm{P} 3 \mathrm{HT})$; Device II: $\left(\mathrm{ZnO} / \mathrm{P} 3 \mathrm{HT}: \mathrm{TiO}_{2}\right)$; Device III: $\left(\mathrm{ZnO} / \mathrm{TiO}_{2}\right.$ nanorods/P3HT: $\left.\mathrm{TiO}_{2}\right)$. 
Table 1 Summary of the device performance of different configurations: Device I: (ZnO/P3HT); Device II: ( $\left.\mathrm{ZnO} / \mathrm{P} 3 \mathrm{HT}: \mathrm{TiO}_{2}\right)$; Device III: $\left(\mathrm{ZnO} / \mathrm{TiO}_{2}\right.$ nanorods/P3HT:TiO $)$; Device IV: $\left(\mathrm{ZnO} / \mathrm{TiO}_{2}\right.$ nanorods/ $\mathrm{P} 3 \mathrm{HT}: \mathrm{TiO}_{2}$ ) through pyridine treatment

\begin{tabular}{lllll}
\hline & $J_{\mathrm{sc}} / \mathrm{mA} \mathrm{cm}^{-2}$ & $V_{\mathrm{od}} / \mathrm{mV}$ & $\mathrm{FF}$ & $\eta(\%)$ \\
\hline Device I & 0.30 & 335 & 0.40 & 0.04 \\
Device II & 1.96 & 380 & 0.39 & 0.29 \\
Device III & 2.20 & 400 & 0.35 & 0.31 \\
Device IV & 2.67 & 490 & 0.45 & 0.59 \\
\hline
\end{tabular}

to their usage of smaller diameter $\mathrm{ZnO}$ nanofibers, which can be infiltrated into more photoactive materials with a higher light harvesting efficiency. Device II has the configuration of $\mathrm{ZnO} / \mathrm{P} 3 \mathrm{HT}: \mathrm{TiO}_{2}$ nanorod hybrid and exhibits values for $J_{\mathrm{sc}}$, $V_{\mathrm{oc}}, \mathrm{FF}$, and $\eta$ of $1.96 \mathrm{~mA} \mathrm{~cm}{ }^{-2}, 380 \mathrm{mV}, 0.39$, and $0.29 \%$ respectively. Over six times increase in $J_{\mathrm{sc}}$ with respect to Device I is achieved due to increased charge separation and transport efficiency after the inclusion of $\mathrm{TiO}_{2}$ nanorods in the polymer. Device III has the configuration of $\mathrm{ZnO} / \mathrm{TiO}_{2} /$ P3HT:TiO ${ }_{2}$ by pre-coating a thin $\mathrm{TiO}_{2}$ nanorod film onto $\mathrm{ZnO}$ nanorods before the infiltration of the $\mathrm{P} 3 \mathrm{HT}: \mathrm{TiO}_{2}$ nanorod hybrid. The device shows $J_{\mathrm{sc}}, \mathrm{V}_{\mathrm{oc}}, \mathrm{FF}$, and $\eta$ performance of $2.20 \mathrm{~mA} \mathrm{~cm}{ }^{-2}, 400 \mathrm{mV}, 0.35$, and $0.31 \%$ respectively. The further increase in $J_{\mathrm{sc}}$ of Device III compared to that in Device II is attributed to the addition of the thin $\mathrm{TiO}_{2}$ nanorod layer, which prevents electrons from back recombining with holes in P3HT and allows for the photogenerated current to be colleted more effectively. Table 1 summarizes the device performance for different configurations. From the photovoltaic performance of the above devices with different configurations, it is found that the inclusion of $\mathrm{TiO}_{2}$ nanorods in the $\mathrm{ZnO} / \mathrm{P} 3 \mathrm{HT}$ nanostructured hybrid solar cell can improve the device performance by providing increased interfacial area and a more effective transport pathway. Fig. 8 shows the photovoltaic response decay curves of Devices I and III at the zero bias condition under pulsed laser illumination. A faster responding time $(\sim 0.5 \mu \mathrm{s})$ for the device with the configuration $\mathrm{ZnO} / \mathrm{TiO}_{2} / \mathrm{P} 3 \mathrm{HT}: \mathrm{TiO}_{2}$ (Device III) with respect to the device consisting of a neat P3HT film on $\mathrm{ZnO}$ nanorods (Device I)

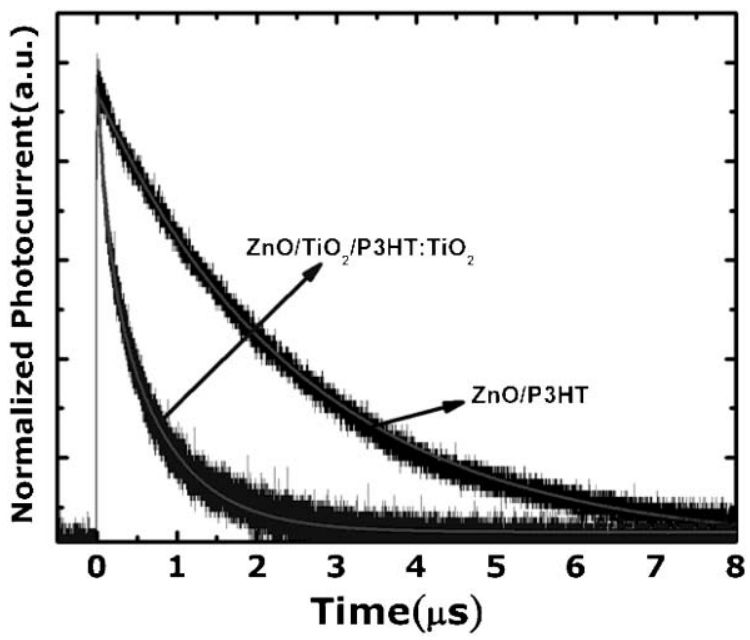

Fig. 8 Fast transient photocurrent decay for Device I ( $\mathrm{ZnO} / \mathrm{P} 3 \mathrm{HT})$ and Device $\mathrm{III}\left(\mathrm{ZnO} / \mathrm{TiO}_{2}\right.$ nanorods $\left./ \mathrm{P} 3 \mathrm{HT}: \mathrm{TiO}_{2}\right)$ respectively. $(\sim 3.0 \mu \mathrm{s})$ was found, indicating that effective carrier transport can be achieved through this design of hybrid architecture.

In addition, it is suggested that the device performance for the polymer/nanocrystal hybrid solar cells can be further enhanced by completely removing the possible residual surfactant in the hybrid. ${ }^{9}$ We have therefore carried out the process of ligand exchange to remove the residual surfactant oleic acid (OA) through pyridine treatment according to the literature. ${ }^{26}$ The as-synthesized $\mathrm{OA}$ end-capped $\mathrm{TiO}_{2}$ nanorods were dispersed in pyridine and left stirring at $70{ }^{\circ} \mathrm{C}$ until the solution turned clear. Afterwards, the treated nanocrystals were washed with hexane and isolated by centrifugation, and redispersed in pyridine. Through these procedures, the OA (original surface ligand) was removed and the pyridine of a weak binding ligand was on the surface of $\mathrm{TiO}_{2}$ nanorods, which can be removed through heating. Following the same device fabrication procedures as above, Device IV has a similar configuration to Device III of $\mathrm{ZnO} / \mathrm{TiO}_{2} / \mathrm{P} 3 \mathrm{HT}: \mathrm{TiO}_{2}$ by pyridine treatment and shows a short circuit current density

(a)

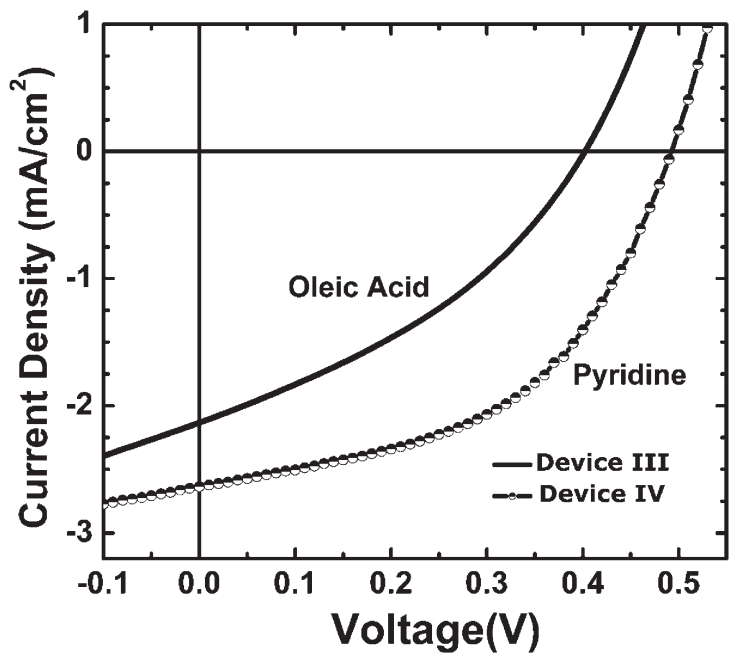

(b)

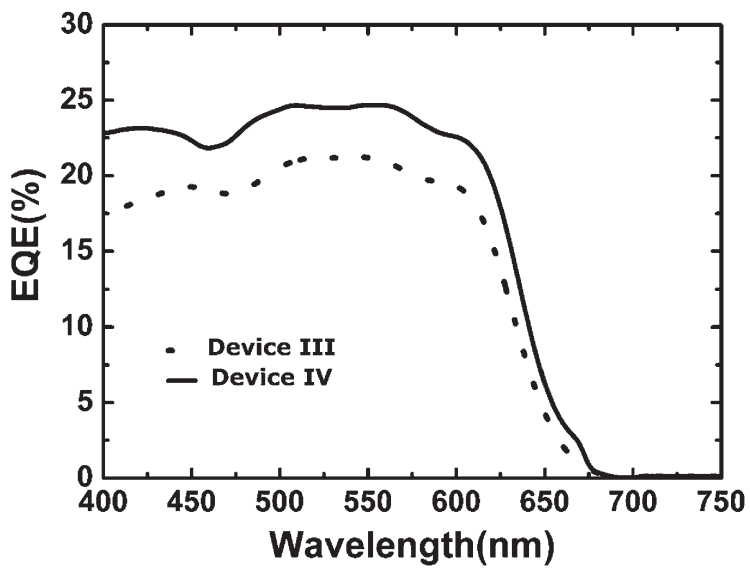

Fig. 9 (a) Photovoltaic performances of the devices before (Device III) and after (Device IV) removing the surfactant (OA) on the $\mathrm{TiO}_{2}$ nanorods by pyridine treatment. Both the devices have the configuration $\mathrm{ZnO} / \mathrm{TiO}_{2}$ nanorods/P3HT: $\mathrm{TiO}_{2}$ hybrids. (b) The corresponding external quantum efficiencies (EQE) of Device IV. 
$\left(J_{\mathrm{sc}}\right)$ of $2.67 \mathrm{~mA} \mathrm{~cm}^{-2}$, an open circuit voltage $\left(V_{\mathrm{oc}}\right)$ of $490 \mathrm{mV}$, a fill factor (FF) of 0.45 , and a power conversion efficiency $\eta$ of $0.59 \%$ as shown in Fig. 9(a), giving an improvement by nearly a factor of two. The corresponding external quantum efficiency (EQE) of Device IV is shown in Fig. 9(b), which has a maximum value of $24 \%$ at $510 \mathrm{~nm}$. Complete removal of the residual surfactant at the $\mathrm{P} 3 \mathrm{HT} / \mathrm{TiO}_{2}$ nanorod interfaces leads to direct contact between the polymer and the $\mathrm{TiO}_{2}$ nanorods by removing the insulating barrier, leading to a further improvement in charge separation and transport efficiencies. In addition, the increase in the open circuit voltage $V_{\text {oc }}$ after pyridine treatment may be attributed to the change in interfacial dipoles, leading to a shift in the band offset at the $\mathrm{TiO}_{2}$ - polymer interface. ${ }^{27}$

\section{Conclusion}

In summary, we have proposed a type of nanostructured polymer/inorganic metal oxide hybrid photovoltaic device through low temperature solution processes. Thicker nanorstructured $\mathrm{ZnO}$ nanorods are grown on the electrode surface to provide direct pathways for efficient charge collection. Thinner $\mathrm{TiO}_{2}$ nanorods are incorporated into the polymer to facilitate charge separation and transport by providing increased interfacial area and an effective transport pathway. Considerable improvement in the device performance is achieved by infiltrating the $\mathrm{P} 3 \mathrm{HT}: \mathrm{TiO}_{2}$ nanorod hybrid into $\mathrm{ZnO}$ nanorod arrays with respect to that without the incorporation of $\mathrm{TiO}_{2}$ nanorods. The device performance can be further enhanced after completely removing the residual surfactant in the $\mathrm{P} 3 \mathrm{HT}: \mathrm{TiO}_{2}$ nanorod hybrid after pyridine treatment.

\section{Acknowledgements}

This work is supported by National Science Council, Taiwan (Project No. NSC95-2120-M-002-004) and the US Airforce project (AOARD 064-044).

\section{References}

1 M. Graetzel, Nature, 2001, 414, 338.

2 W. U. Huynh, J. J. Dittmer and A. P. Alivisatos, Science, 2002, 295, 2425.
3 W. Ma, C. Yang, X. Gong, K. Lee and A. J. Heeger, Adv. Funct. Mater., 2005, 15, 1617.

4 R. H. Friend, G. J. Denton, J. J. M. Halls, N. T. Harrison, A. B. Holmes, A. Kohler, A. Lux, S. C. Moratti, K. Pichler, N. Tessler, K. Towns and H. F. Wittmann, Solid State Commun., 1997, 102, 249

5 T. J. Savenije, J. M. Warman and A. Goossens, Chem. Phys. Lett., 1998, 287, 148.

6 A. C. Arango, L. R. Johnson, V. N. Bliznyuk, Z. Schlesinger, S. A. Carter and H. H. Horhold, Adv. Mater., 2000, 12, 1689.

7 G. Yu and A. J. Heeger, J. Appl. Phys., 2001, 78, 4510.

8 A. Haugeneder, M. Neges, C. Kallinger, W. Spirk1, U. Lemmer and J. Felmann, Phys. Rev. B, 1999, 59, 15346.

9 N. C. Greenham, X. Peng and A. P. Alivisatos, Phys. Rev. B, 1996, 54, 17628.

10 J. S. Salafsky, Phys. Rev. B, 1999, 59, 10885.

11 C. Y. Kwong, W. C. H. Choy, A. B. Djurisic, P. C. Chui, K. W. Cheng and W. K. Chan, Nanotechnology, 2004, 15, 1156.

12 T. W. Zeng, Y. Y. Lin, His-Hsing Lo, C. W. Chen, ChengHsuan Chen, Sz-Chian Liou, Hong-Yun Hunag and Wei-Fang Su, Nanotechnology, 2006, 15, 5387.

13 W. J. E. Beek, M. M. Wienk and R. A. J. Janssen, Adv. Mater., 2004, 16, 1009.

14 K. M. Coakley and M. D. McGehee, Appl. Phys. Lett., 2003, 83, 3380.

15 K. M. Coakley, Y. X. Liu, M. D. McGehee, K. L. Frindell and G. D. Stucky, Adv. Funct. Mater., 2003, 13, 301.

16 P. Ravirajan, S. A. Haque, J. R. Durrant, D. D. C. Bradley and J. Nelson, Adv. Funct. Mater., 2005, 15, 609.

17 H. Wang, C. C. Oey, A. B. Djurisic, M. H. Xie, Y. H. Leung, K. K. Y. Man, W. K. Chan, A. Pandey, J. M. Nunzi and P. C. Chui, Appl. Phys. Lett., 2005, 87, 023507.

18 Q. Wei, K. Hirota, K. Tajima and K. Hashimoto, Chem. Mater., 2006, 18, 5080

19 P. Ravirajan, A. M. Peiró, M. K. Nazeeruddin, M. Graetzel, D. D. C. Bradley, J. R. Durrant and J. Nelson, J. Phys. Chem. B, 2006, 110, 7635.

20 D. C. Olson, J. Piris, R. T. Collins, S. E. Shaheen and D. S. Ginley, Thin Solid Films, 2006, 496, 26.

21 P. D. Cozzoli, A. Kornowski and H. Weller, J. Am. Chem. Soc., 2003, 125, 14539.

22 Y. T. Lin, T. W. Zeng, W. Z. Lai, C. W. Chen, Y. Y. Lin, Y. S. Chang and W. F. Su, Nanotechnology, 2006, 17, 5781.

23 D. H. Auston, IEEE J. Quantum Electron., 1983, 19, 639.

24 Y. Y. Lin, C. W. Chen, J. Chang, T. Y. Lin, Y. S. Liu and W. F. Su, Nanotechnology, 2006, 17, 1260.

25 M. Law, L. E. Greene, A. Radenovic, T. Kuykendall, J. Liphardt and P. Yang, J. Phys. Chem. B, 2006, 110, 22652.

26 W. U. Huynh, J. J. Dittmer, W. C. Libby, G. L. Whiting and A. P. Alivisatos, Adv. Funct. Mater., 2003, 13, 73.

27 Y. Liu, S. R. Scully, M. D. McGehee, J. Liu, C. K. Luscombe, J. M. J.Frechet, S. E. Shaheen and D. S. Giniey, J. Phys. Chem. B, 2006, 110, 3257. 